\title{
頭蓋内動脈瘤を伴う内頸動脈狭窄症に対する外科的治療
}

\author{
その適応と考察
}

\author{
梶原 秀彦・児玉 万典・伊東山洋一・松角 康彦・福村 昭信*
}

\section{Surgical Treatment of the Symptomatic Carotid Stenosis associated with Unmoptured Ipsilateral Intracranial Aneurysm}

\author{
Case Report
}

Hidehiko KajIWARA, Takafumi Kodama, Yoichi ItOYama, Yasuhiko MatsuKado and Akinobu FukUMURA*

Department of Neurosurgery, Kumamoto University, Kumamoto; ${ }^{*}$ Neurosurgical Section, Shimonoseki Kosei Hospital, Shimonoseki, Yamaguchi

\begin{abstract}
Surgical treatment of the symptomatic carotid stenosis associated with ipsilateral intracranial aneurysm requires special strategic consideration. A 56-year-old housewife was admitted to a local hospital with a history of mild hypertension and recent episodes of recurrent transient ischemic attacks of the right cerebral hemisphere. Carotid angiography revealed bilateral stenosis of the carotid artery, $90 \%$ stenosis with ulcer on the right and $50 \%$ smooth surfaced stenosis on the left, middle cerebral trifurcation aneurysm on the right, internal carotid aneurysm in the left cavernous portion, and aplasia of the left anterior cerebral artery at its horizontal portion. She was referred for surgery. Neurological examination revealed a slightly disturbed mentality. During hospitalization she developed left hemiparesis and computerized tomography scan demonstrated right frontal watershed infarction. One month after the onset of cerebral infarction, operative treatment was attempted with special care to prevent lowering systolic blood pressure during procedure. The right middle cerebral artery aneurysm was first clipped, and right carotid endarterectomy was performed, while mannitol and barbiturate were administered without resort to internal shunt. Postoperatively the left hemiparesis improved gradually.

Twenty-seven cases of the carotid stenosis associated with intracranial aneurysm(s) were collected from the literature and the strategic problems of these cases are discussed.
\end{abstract}

Key words: carotid stenosis, intracranial aneurysm, operative treatment, indication

\section{I はじめに}

頸部頸動脈閉塞性病变は，欧米において注虚血性脳血管 障害患者の60〜90\%に発見され，その46〜 75\%が神経機能

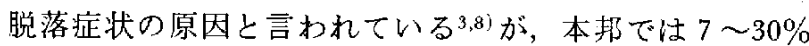
と欧米に比較して少ない14．一才，クモ膜下出盂(SAH)
による死亡率は，人口10万人当り本邦では 25 人，米国では 16人と本邦にやや多く20)，その大部分は脸動脈瘤破裂に上 るものである，このように，頸部頸動脈狭窄症と脳動脈瘤 とは拧の㧍の比較的多い疾患であるが，その合併例の報告 は少なく諸外国において散見されるのみである1,5,9,15,18,22． 最近我々は，一過性脳虚血発作(TIA)で発症し，未破裂 
脳動脈瘤を合併する頸部頸動脈狭害症の1例を経験したの で，その治療法を中心文献的考察を加えて報告する。

\section{II 症例}

〈患者〉56才，主婦

主訴：左上下肢の反復性・一過性脱力発作

家族歴：母親に高血圧症，妹に肺結核

既往歴：20年前より高血压を指摘されていたが放置して いた。

現病歴：1982年 1 月頃より全身傥急感をきたし気分不良 となるため近医を受診し，高血圧を指摘され降圧郕の投与 を受けた．8月初旬から左上下肢の一過性脱力発作が 3 回 出現し，8月9日某医に入院した。るの際，神経学的に法 異常はなかったが，脳血管撮影にて総頸動脈分岐部の動脈 硬化性狭窄上脳動脈瘤を指摘され，8月30日手術目的で当 科一転院となった。

当科入院時所見：全身僚虫感，体動時の動摇感，噪気が あり，ほぼ bedriddenの状態であった，脈拍60/min(整)， 血圧 $160 / 100 \mathrm{mmHg}$ で，駆出性心雑音と右頸部の bruit 聴取し，神程学的には軽度の記銘力・計算力障害，全般性 深部腱反射充進があり，眼底は Keith-Wagener II 度であ った．血液一般検查では，血沈の克進 $(85 \mathrm{~mm} / \mathrm{hr})$ ，白血 球減少 $\left(2,800 / \mathrm{mm}^{3}\right)$ が認められ，抗核抗体陽性であった。 脂筫代谢では，総コレステロール $186 \mathrm{mg} / \mathrm{d} l$ ，中性脂肪 66 $\mathrm{mg} / \mathrm{d} l, \quad$ NEFA $260 \mu \mathrm{Eq} / l, \mathrm{HDL}$ コレステロール $30 \mathrm{mg} / \mathrm{d} l$ と，HDL コレステロールがやや低值であった。また，右 頸動脈撮影( Fig. 1)にて，頸動脈分岐部内頸動脈に不整な 潰瘍形成を伴う $90 \%$ 以上の狭窄があり，中大脳動脈分岐部 に直畦 $5 \mathrm{~mm} の$ saccular aneurysm が認められた。前大脳

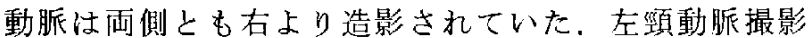
（Fig. 2）では，頸動脈分岐部内頸動脈に50\%の狭窄を䐂め たが，平滑で潰疾の所見はなかった。 また海綿静脈洞部に 動脈瘤が認められ，左前大脳動脈 $\mathrm{A}_{1}$ 部は欠損していた。 頭蓋内血管には明らかな狭窄像はなく，後交通動脈は両側 とも造影されていなかった。椎骨動脈撮影は, catheterization 不可能であったため断念した，その他，CT scanでは 側脳室の軽度の非対称以外異常所見はなく，99mTc-DTPA 静注法に上る希积曲線上り求めた relative cerebral blood flow では，左半球に比し右半球の血流低下が推測された。 脳波では左前頭部，右全般性に徐波の混入がみられ， somatosensory evoked potential でも右大脳半球の機能低下 を示す所見が認められた。

入院後経過：入院後原因不明の発熱が 1 週間続き，血液 検査所見と合わせ膠原病が疑われ内科的精查を行った，㛟 査の結果，膠原病は否定されたが，9月18日左片麻疩・左
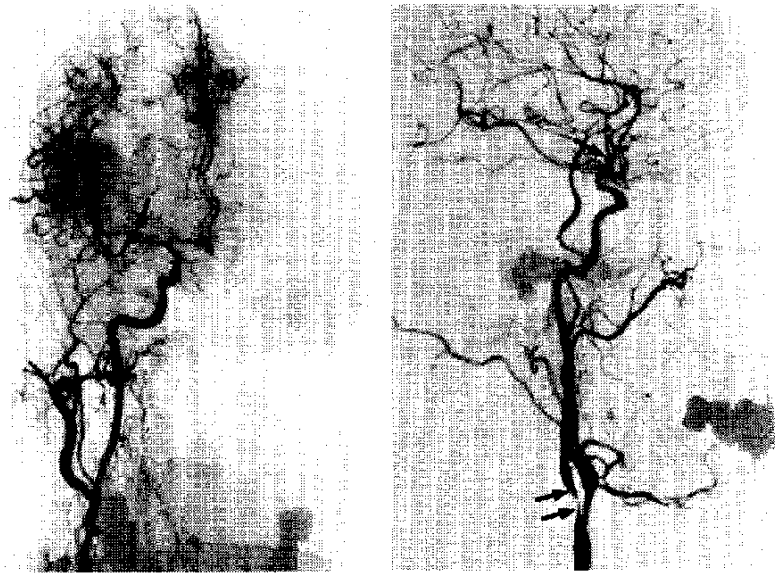

Fig. 1 Right carotid angiograms showing marked stenosis of the common carotid bifurcation (arrows) and a saccular aneurysm arising from the bifurcation of the right midde cerebral artery (arrow). Bilateral anterior cerebral arteries are filled by right side injection.
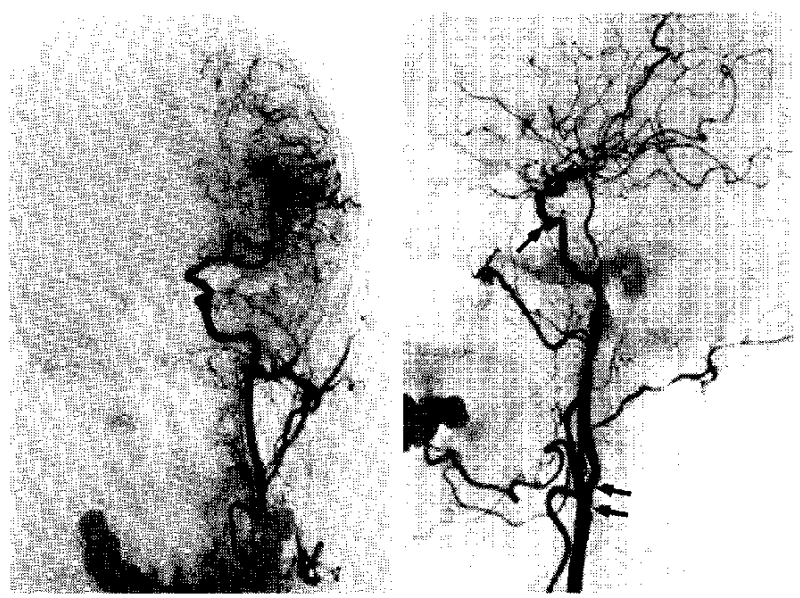

Fig. 2 Left carotid angiograms showing smooth surfaced stenosis of the common carotid bifurcation (arrows) and an aneurysm arising from the cavernous portion of the internal carotid artery (arrow). The horizontal portion of the left anterior cerebral artery is not visualized.

半身知覚障害が出現し，CT scanにて右前頭葉の watershed 領域に低吸収域が認められた。左片麻疩は徐々に改善 傾向を示し，follow up CT scan では低吸收域の contrast enhancement は認められなかった(Fig. 3)。10月26日，右 中大脳動脈瘤 clipping に引き続き，頸動脈内膜䟝離術 (CEA)を施行した。一方，左大脑半球の症状はなく，左 頸動脈の狭窄部は平滑でその艮度も軽度であり，動脈瘤は 海綿静脈洞部に存在することより左側の手術は行わなかっ 

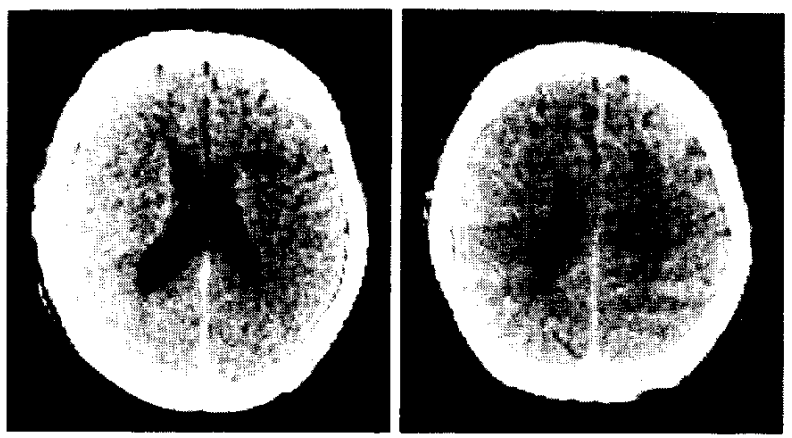

Fig. 3 Contrast enhanced computerized tomography scan showing a watershed infarction in the right frontal region without contrast enhancement.

たなお，この症例の手術術式として，右頸動脈の㷋窄の 程度が強いこと，および左右の前人脳動脈の交通もないこ とより，CEA 後の血流増加は直接的に動脈瘤内医に反映 される危険があると考え，CEAに先立ち動脈瘤の clippingを行った.

手術所見：GOF, thiamylal 投与下に全身麻醇を行い, pterional approachにて右中大脳動脈分岥部動脈瘤の neck clipping 施行した。動脈瘤は，以前に出血した形跡はな かったが bleb 在伴っていた，術中血压注150/80 mmHg 以 上に維持し，開頭時 $20 \%$ mannitol $300 \mathrm{~m} l$ を投与した。さ らに, CEA 前に mannitol $600 \mathrm{ml}$, heparin 2,000 I.U. を投 与した。 CEAに際しては内シャントの使用も考えたが， 内頸動脈は全体的に細くシャントの㨀入に困難が予想され たため，シャント在使用せずに CEA 行った。血行遮断 時間は35分間であった，術中 stump pressure の測定は行っ ていないが，back flow は不良であった，CEA 終了後，収 樎期血压は $250 \mathrm{mmHg}$ と上昇したが， hexamethonium bromideにてコントロールされた，摘出された組織は潰瘍 を有する典型的な atheromatous plaque であった。

術後経過：術後左片麻㾖は徐々に改善し，術前誌められ た不快な気分や体動時の動摇感も消失した。Digital subtraction angiographyにてCEA 部の通過老確認し(Fig. 4), 12月11日独歩退院した。

\section{III 考察}

頸部頸動脈狭窄症と脳動脈㨫との合併の報告は少なく， 我々が文献上調べえた範囲では，我々の症例を含めて28例 である。これら 2 病变の合併頻度について, Gurdjian $ら^{10 /}$ は頸動脈病変のために血管撮影を行った205例中 6 例 $(2.9 \%)$ に脳動脈溜を認め，Silverstein ${ }^{19)}$ は臨床的に脳血管 閉塞性病变として血管撮影を受けた252例中6 例(2.4\%)に

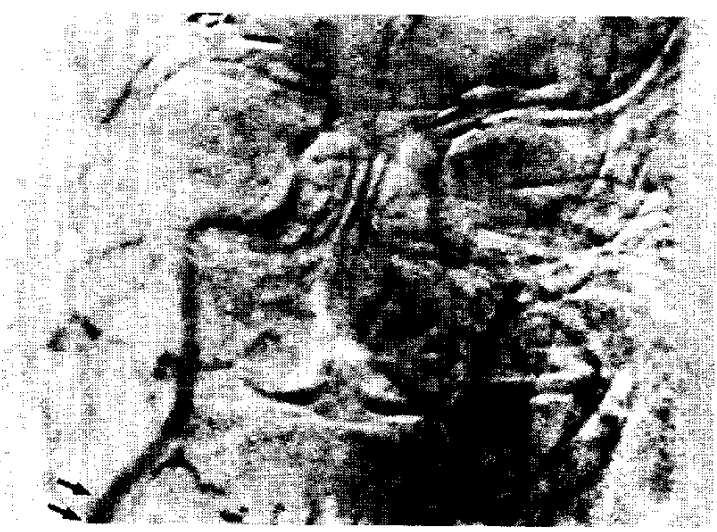

Fig. 4 Postoperative digital subtraction angiograph of the right carotid artery indicating sufficient recanalization (arrows).

脳動脈瘤および畄動静脈奇形を認めている。また， Baker ${ }^{3 !}$ は TIA 患者217例中10例（4.6\%)に脳動脈瘤老合併 していたと報告している。一方，McCormick ら ${ }^{12 i}$ は末破 裂脳動脈瘤は人山の4〜6\%に認められると述べておう， 頸部頸動脈狭窄症と脳動脈㨨との合併沬，いわゆる in cidental aneurysm の頻度とほぼ同程度かそれ以下と推定 され，両者間には特に因果関保はないと思われる211。

今回の報告例を含む28例をその臨床症状より，SAHあ るいは動脈瘤の局所症状で発症した SAH 群( Table 1) と， 脳虚血発作で発症したTIA 群( Table 2)に大別した。症例 数は SAH 群 7 例に対し TIA 群21例と TIA 群が王倒的に 多く，こ机は脎虚血性疾患の発生頻度が高いことに中来す ると思われる。頸動脈病変は，記載のない Fields ら ${ }^{9 /} の$ 症 例以外は全例㹨窄度70\%以上である。年齿注43〜84才で, 平均は SAH 群58才，TIA 群63才でSAH 群がやや若く， 性別では不明なものが多いが記載のあるものはすべて女性 であった。頸部頸動脈病变上脳動脈瘤との局在をみると, TIA 群では両病変が同側にあるものは21例中19例，SAH 群では同側にあるもの3 例，対側にあるもの4例(うち2 例は large aneurysm) と相違を示し, SAH の発生に頸動脈 狭窄に伴う hemodynamic change の関与す推測される。脳 動脈瘤の局在は両群上も内頸動脈に多くみられるが，TIA 群の内頸動脈采18個のうち 6 個が海綿静脈洞部であった点 が特異であった. Jellinger ${ }^{11)}$ は，海綿静脈洞部動脈瘤は40 才以上の高血压を有する女性に多く， arteriosclerosis を伴 5と述べている.

頸部頸動脈狭窄㾜と脳動脈瘤合併例に対する外科的治療 の手技としては, 従来脳血流量低下時の脳動脈溜一の直達 手術は仵険性が高いとされ，まずCEAを行うのが一般的 
Table 1 Reported cases presenting subarachnoid hemorrhage or local signs of cerebral aneurysm with incidental carotid stenosis

\begin{tabular}{|c|c|c|c|c|c|}
\hline $\begin{array}{l}\text { Case } \\
\text { No. }\end{array}$ & Author & $\begin{array}{l}\text { Age, } \\
\text { Sex }\end{array}$ & $\begin{array}{l}\text { Location of } \\
\text { aneurysm }\end{array}$ & $\begin{array}{l}\text { Side of } \\
\text { IC stenosis }\end{array}$ & Operation \\
\hline 1 & Fields $e t a l^{8}$ & $67, \mathrm{~F}$ & rt. ICPC & $\begin{array}{l}\text { bilateral } \\
(\text { lt. } \$ \mathrm{rt} .)\end{array}$ & $\begin{array}{l}\text { rt. carotid ligation } \\
\text { lt. CEA }\end{array}$ \\
\hline 2 & Portnoy et al. ${ }^{15)}$ & $69, \mathbf{F}$ & rt. ICPC & It. $(90 \%)$ & 1t. CEA-clipping \\
\hline 3 & Stern el al. ${ }^{221}$ & 48 & $\begin{array}{l}\text { rt. ICPC } \\
\text { (large) }\end{array}$ & lt. & lt. CEA-clipping \\
\hline 5 & $n$ & 57 & $\begin{array}{l}\text { rt. ICPC } \\
\text { lt. ICPC } \\
\text { lt. AVM }\end{array}$ & rt. & clipping-rt. CEA \\
\hline 6 & $"$ & 60 & $\begin{array}{l}\text { rt. IC } \\
\text { lt. IC }\end{array}$ & rt. & clipping-rt. GEA \\
\hline 7 & $"$ & 43 & It. ACA & It. & clipping-lt. CEA \\
\hline
\end{tabular}

ICPC indicates internal carotid-posterior communicating artery; IC, internal carotid artery; ACA, anterior cerebral artery; AVM, arteriovenous malformation; CEA, carotid endarterectomy.

Table 2 Reported cases presenting transient ischemic attack with incidental cerebral aneurysm

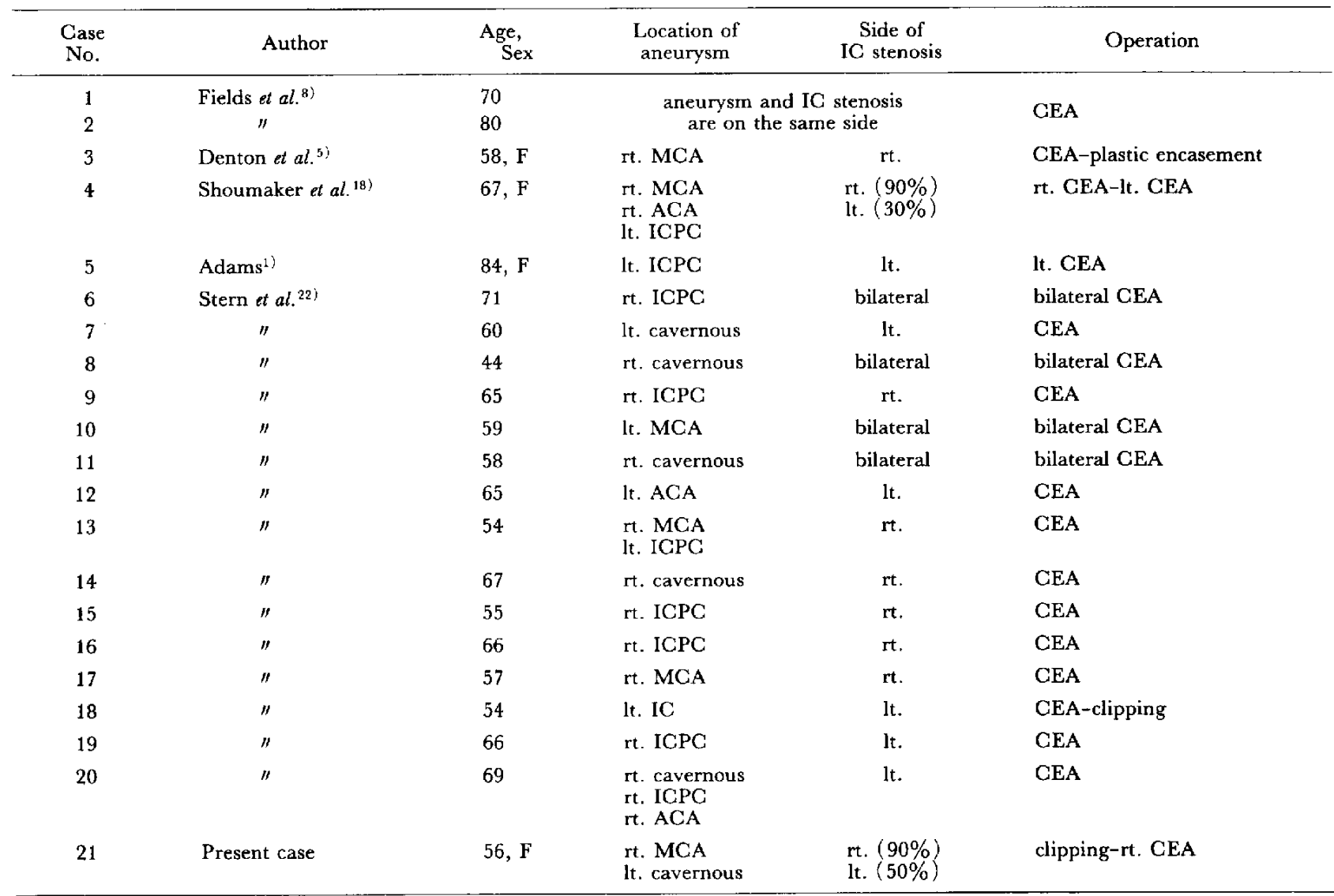

ICPC indicates internal carotid-posterior communicating artery; IC, internal carotid artery; ACA, anterior cerebral artery; MCA, middle cerebral artery; CEA, carotid endarterectomy. 
であった. Stern ら 221は治療法の選択について，(1)どちら の病変が symptomatic なのか, (2)動脈瘤による症状は SAHによるのか，あるいは動脈瘤の增大によるのか，(3) 2 つの病変は同側か対側か，によって治療法を決定すべき であることを指摘し，SAH群の場合，同側の病変では動 脈㾴への直達手術から，対側の病変では CEA から行うこ とを推奖しており，この点に関しては異論のないものと思 われる，一方，TIA 群に対する外科的治療については議 論の分かれるところであるが，それは CEA が動脈瘤破裂 の原因となるのか，西るいは促進因子となるのかという点 に関わっていると思われる。理論的には頸動脈狭窄度が 70〜90\%以上の場合，狭窄部より末梢の血圧・血流は低下 しており ${ }^{23 !}$ ，逆に狭窄が解除されれば動脈瘤内圧，turbulence は增加し動脈瘤破裂の危険性を高好と考えられ $る^{6,7)}$. Denton $5^{5)}$ は GEA 後 1 週目の血管撮影で動脈瘤 $の$ emptying time の短縮諗め, plastic encasement 施行 した 1 例を報告している。これに反し，Fields ら Shournaker ら ${ }^{13)}$, Stern ら ${ }^{22 !}$ は CEAのみを行った17例〈う ち 2 例は対側病変)に対して, 術後 6 力月〜 1 年で脳血管 撮影を行い，動脈瘤の堌大は認められず SAH の発症例も なかったことより，CEAは未破裂脳動脈瘤破裂の危険性 を高めるものではないと結論した，しかし，CEAの動脈 瘤に対寸る影響を考える場合，動脈溜の大きさ，部位， Willis 輪を介寸る左右の交通性，TIA の病態が hemodynamic change によるのか, microembolismに上るのかな どの点を考慮に入れる必要があると思われ，概括的に結論 を下すことは危険であると考える，さらに，脳血管撮影の follow upにて動脈瘤破裂の危険性を判断していることに も問題があると思われる.Allcock ら ${ }^{2}$ は脳動脈瘤の増大 率は症例によって異なるため予測困難であり，ごく小さな 動脈㨨以外は血管撮影による経過觀察は賢明でないと指摘 している，頸動脈怢窄症に合併寸る未破裂動脈瘤も， CEA 後は少なくとも一般の incidental aneurysm と同様に $5 \sim 10 \%$ に破裂の危険性があると考えられ，患者の状態が 許寸かぎり積極的に外科的治撩を行うべきであると思われ

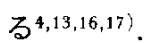

我々の症例は，頸部頸動脈狭焦の程度が強く左右の内頸 動脈系の交通むないこと，さらに hypoperfusionによると 思われる脳梗塞の既往があることより，CEA お上び clipping 術のどちらに対しても高リスク患者であった。このよ うな症例比対し, 術中血圧の維持を中心とする麻酔管理, mannitol や barbiturate などの脳保護凨の積極的な投与下 において, clipping 術ならびに non-shuntでの CEAを一 次的に行い良好な結果が得られたことは，わずか 1 例では あるがこれらの病変に対する approach について示唆する
ところは大きいと思われた。

\section{IV 結 語}

未破裂脳動脈瘤去合併した頸部頸動脈狭窄症の1例を報 告し，その外科的治療法を中心に文献的考察を加えた。

\section{文献}

1) Adams HP Jr: Carotid stenosis and coexisting ipsilateral intracranial aneurysm. A problem in management. Arch Neurol 34: $515-516,1977$

2) Allcock JM, Canham PB: Angiographic study of the growth of intracranial aneurysms. J Neurosurg 45: 617-621, 1976

3) Baker HL Jr: Medical and surgical care of stroke. Roentgenologic aspects. Circulation 32: 559-562, 1965

4) Dell S: Asymptomatic cerebral aneurysm. Assessment of its risk of rupture. Neurosurgery 10: 162-166, 1982

5) Denton IC, Gutmann L: Surgical treatment of symptomatic carotid stenosis and asymptomatic ipsilateral intracranial aneurysm. Case report. I Neurosurg 38: 662-665, 1970

6) Ferguson GG: Turbulence in human intracranial saccular aneurysms. J Neurosurg 33: 485-497, 1970

7) Ferguson GG: Direct measurement of mean and pulsatile blood pressure at operation in human intracranial saccular aneurysms. J Neurosurg 36: 560-563, 1972

8) Fields WS, North RR, Hass WK, Galbraith JG, Wylie EJ, Ratinov G, Burns MH, McDonald MC, Meyer JS: Joint study of extracranial arterial occlusion as a cause of stroke. I. Organization of study of patient population. JAMA 203: 955-960, 1968

9) Fields WS, Weibel J: Coincidental internal carotid stenosis and intracranial saccular aneurysm. Trans Am Neurol Assoc 95: 237238,1970

10) Gurdjian ES, Hardy WG, Lindner DW, Thomas LM: Diagnostic evaluation and treatment. Symposium: Occlusive cerebrovascular disease. Trans Amer Acad Ophthal Otolaryng 66: 149-165, 1962

11) Jellinger K: Pathology and aetiology of intracranial aneurysms, in Pia HW, Langmaid C, Zierski J (eds): Cerebral Aneurysms. Advances in Diagnosis and Therapy. Berlin, Springer, 1979, pp 5-19

12) McCormick WF, Rosenfield DB: Massive brain hemorrhage. A review of 144 cases and an examination of their cases. Stroke 4: 946-954, 1973

13) Ojemann RG: Management of the unruptured intracranial aneurysm. $N$ Engl J Med 304: 725-726, 1981

14）小野博久：頸部暊動脈閉塞性病变の修復。日外会誌 80: 1607-1611, 1977

15) Portnoy HD, Avellanosa A: Carotid aneurysm and contralateral carotid stenosis with successful surgical treatment of both lesions. Case report. J Neurosurg 32: 476-482, 1970

16) Salazar JL: Surgical treatment of asymptomatic and incidental intracranial aneurysms. $J$ Neurosurg 55: 20-21, 1980

17) Samson DS, Hodosh RM, Clark WK: Surgical management of 
unruptured asymptomatic aneurysms. $J$ Neurosurg 46: 731-734, 1977

18) Shoumaker RD, Avant WS, Cohen MGH: Coincidental multiple asymptomatic intracranial aneurysms and symptomatic carotid stenosis. Stroke 7: 504-506, 1976

19) Silverstein A: Arteriography of stroke. I, Incidence of mass lesion in patients with clinical diagnosis of occlusive cerebrovascular disease. Arch Neurol 12: 387-389, 1965

20) Smith RR: Pathophysiology and clinical evaluation of subarachnoid hemorrhage, in Youmans JR (ed): Neurological Surgery, vol 3, ed 2. Philadelphia, WB Saunders, 1982, pp 1627-1644

21) Spallone A, Cantore $G$ : The role of extracranial carotid abnormalities in the genesis of cerebral aneurysms. J Neurosurg 55: 693-
700,1981

22) Stern J, Whelan M, Brisman R, Correll JW: Management of extracranial carotid stenosis and intracranial aneurysms. $J$ Neurosurg 51: 147-150, 1979

23) Tindall GT, Odom GL, Cupp HB Jr, Dillon ML: Studies on carotid artery flow and pressure. Observations in 18 patients during graded occlusion of proximal carotid artery. J Neurosurg 19 : 917-923, 1962

〔別刷請求先：干860 熊本市本乼 1-1-1, 熊本大学脳神释外科, 梶原秀彦] 